Article

\title{
Centrality of Religiosity, Schizotypy, and Human Values: The Impact of Religious Affiliation
}

\author{
Paul H. P. Hanel ${ }^{1, *(\mathbb{D}}$, Sarah Demmrich ${ }^{2}$ and Uwe Wolfradt ${ }^{3}$ \\ 1 Department of Psychology, University of Bath, Claverton Down, Bath BA2 7AY, UK \\ 2 Cluster of Excellence Religion and Politics/Sociology of Religion, University of Munster, \\ 48143 Munster, Germany; demmrich.sarah@gmail.com \\ 3 Institute of Psychology, Martin-Luther-University Halle-Wittenberg, 6099 Halle, Germany; \\ uwe.wolfradt@psych.uni-halle.de \\ * Correspondence: p.hanel@bath.ac.uk
}

Received: 27 February 2019; Accepted: 23 April 2019; Published: 28 April 2019

\begin{abstract}
Previous research has established a reliable link between religiosity and schizotypy as well as schizophrenia. However, past research mainly measured religiosity as a one-dimensional construct. In the present research $(\mathrm{N}=189)$, we aimed to get a better understanding of the religiosity-schizotypy link by measuring religiosity using Huber's five-dimensional model of Centrality of Religiosity, while also testing for curvilinear relations and potential moderators. We found negative small-to-medium-sized correlations between all five dimensions of religiosity and the schizotypy dimension of impulsive nonconformity, but no reliable associations with the other three dimensions of schizotypy: unusual experiences, cognitive disorganization, and introverted anhedonia. Some of these associations were moderated by religious affiliation: Religiosity and schizotypy correlated positively among non-members, but negatively among members of religious communities, suggesting that affiliation has a positive impact on the well-being of religious people. In line with Huber's predictions, we found a reversed U-shape association between the religious dimension of private religious practice and schizotypy. Unexpectedly, however, conformity and tradition values did not moderate the relations between religiosity and schizotypy. We discuss our findings in terms of person-environment fit, the prevention hypothesis of the schizotypy-religiosity link, and offer implications for mental health practitioners.
\end{abstract}

Keywords: religiosity; schizotypy; human values; religious affiliation

\section{Introduction}

At 3 a.m. one morning she woke and, after checking that her husband and other children were asleep, took her 3-month-old daughter out of the house, smothered her, and concealed the body in a mesh net in a nearby pond. [... ] When asked about the reason for her behavior she stated that "It needed to be done" and that her mother (who had died 5 years previously) asked her to do it. (Infanticide by a mother with untreated schizophrenia, Saha et al. 2015)

He [God] said, "Take your son, your only son Isaac, whom you love, and go to the land of Moriah, and offer him there as a burnt offering on one of the mountains of which I shall tell you." So Abraham rose early in the morning [... ]. When they came to the place of which God had told him, Abraham built the altar there and laid the wood in order and bound Isaac his son and laid him on the altar, on top of the wood. Then Abraham reached out his hand and took the knife to slaughter his son. (Genesis 22, 2-3a, 9-10) 
Researchers have often postulated and found that there is only a thin line between a religious genius (James [1902] 1928) and a person suffering from schizophrenia. For example, visual hallucinations were often reported in religious and mystical experiences. Thus, the relations between religiosity and schizophrenia have been studied by mental health practitioners and researchers for over 2000 years (Simon 1978). Religion and religiosity are both associated with the psychopathology of psychoses (Mohr and Huguelet 2004). In empirical research, schizotypy is used as a central precursor of schizophrenia. This non-pathological personality trait (Claridge 1994) resembles and predicts schizophrenia symptoms (Hewitt and Claridge 1989; Kerns 2006). Schizotypy is overrepresented among relatives of schizophrenics (Horrobin 1998) and is related to the prodromal period of schizophrenia (Olsen and Rosenbaum 2006). The main characteristics of schizotypy can be classified into three or four dimensions (Claridge et al. 1996; Fonseca-Pedrero et al. 2007; Mason et al. 2005):

- positive symptoms such as perceptual distortions, paranoid ideation, magical thinking, and unusual perceptual/cognitive experiences (e.g., hallucinations, delusions often with a religious or political connotation);

- $\quad$ negative symptoms such as introverted anhedonia (i.e., not enjoying social contact and physical sources of pleasure; introversion);

- a disorganized dimension that includes behavioral and cognitive disorganization (e.g., attentional deficiencies, social anxiety, and emotional sensitivity);

- and an antisocial dimension that includes impulsiveness, nonconformity, poor self-control, and mood swings.

Interviews, questionnaires, and experiential studies uncovered links between schizotypy and religiosity with small to moderate correlations that are influenced by age, gender, and sometimes social desirability (e.g., Hancock and Tiliopoulos 2010; MacPherson and Kelly 2011; Tiliopoulos and Bikker 2013). A strong emphasis lies on experimental explanations of the religiosity-schizotypy link that focuses on a continuum from religious experience/beliefs (normal) to delusional experience/beliefs (abnormal; Jackson 1997, 2001; James [1902] 1928; Mohr and Huguelet 2004; Peters 2001; Smith et al. 2009), whereby this continuum is rooted in a common underlying predisposition of individuals (Dein and Littlewood 2011; Ng 2007; Thalbourne and Delin 1993). Other explanations for the link between religiosity and schizotypy range from excitement-seeking (e.g., schizotypal individuals seek overwhelming sensory stimulation by turning towards religion), prevention (schizotypal individuals use religious explanations for bizarre experiences to decrease the accompanying emotional and cognitive arousal), covariance (schizotypy and religiosity occur together as both are integral parts of one's personality), and spurious correlations (religiosity and schizotypy display phenotypic similarities but are not related in a deep and meaningful way; for an overview see Lesmana and Tiliopoulos 2009).

While previous studies conceptualized and measured schizotypy multidimensionally (Fonseca-Pedrero et al. 2007), the multidimensionality of religiosity was usually neglected, which was criticized by a range of researchers as a limitation of past research (Breslin and Lewis 2015; Day and Peters 1999; Joseph et al. 2002; Ng 2007; Peters et al. 1999; Unterrainer et al. 2011; White et al. 1995). To the best of our knowledge, multidimensional approaches of religiosity in these studies are restricted to prayers (Breslin and Lewis 2015), religious/spiritual well-being (Unterrainer et al. 2011), and intrinsic/extrinsic religious orientation (e.g., Reed and Clarke 2014). The study by Diduca and Joseph (1997) is an exception, which divided delusional thinking as a central aspect of schizotypy into four subdimensions and replaced them with religious terms. The results are four subscales of religious delusions that are located on a cognitive level (e.g., "My thoughts often drift to God") and an emotional level (e.g., "I feel happy when I think about God"), while experiential (e.g., feeling God's presence) and behavioral aspects are neglected (e.g., religious rituals). In contrast, Piedmont (2009) measured the behavioral and experiential dimension of religiosity but did not measure a cognitive or emotional dimension of religiosity. 
In the present study, we investigate for the first time, to the best of our knowledge, the relations between the four dimensions of schizotypy (Mason et al. 2005) and Stefan Huber's (2003; Huber and Huber 2012) comprehensive five-dimensional Centrality and Content of Religiosity model. His model combines the two approaches of the five dimensions of religiosity (Stark and Glock 1968) and intrinsic/extrinsic religious orientation (Allport and Ross 1967). The five dimensions or contents of religiosity, namely intellect (e.g., reading and thinking about religious topics), ideology (e.g., strength of belief in a transcendent dimension), experience (e.g., feeling God's presence), public practice (e.g., church service), and private practice (e.g., prayer) are conceptualized according to their centrality to an individual's personality. Related to centrality, Huber distinguishes between three qualitatively distinct categories: For highly religious individuals, religiosity is central to their lives; therefore, it is internally differentiated (i.e., rich religious experience and behavior) and has a strong influence on everyday life, even beyond the religious domain (e.g., on political attitudes, see Huber et al. 2011). Among religious individuals, religiosity only has a weak influence on non-religious experience and behavior; therefore, religious experience and religious life are barely correlated. Among non-religious people, religiosity is either absent or seldom activated and therefore unstable. Thus, while highly religious individuals have an intrinsic religious orientation (i.e., religion is lived to an end), religious individuals are more likely to have an extrinsic religious orientation (i.e., religion as a means for social and personal gains). Huber's Centrality of Religiosity approach allows us to investigate the relations between five dimensions of religiosity and four dimensions of schizotypy simultaneously, thus potentially revealing relations between these two constructs, which were missed in prior research that operationalized religiosity as a one- or two-dimensional construct (for a discussion about the multidimensionality of religiosity see Oman 2013).

\subsection{Religiosity and Schizotypy: State of Research}

Below we summarize past research on religiosity and schizotypy, separately for the five dimensions of religiosity and intrinsic/extrinsic religious orientations.

Intellect. A general indicator of religious intellect is the frequency of thoughts about God (Huber and Huber 2012). This religious preoccupation appeared to be-under consideration of other religious variables (ideology, religious guidance, and emotional involvement into religion)—-the only predictor of schizotypy (Diduca and Joseph 1997).

Ideology. The continuum explanation of the religiosity-schizotypy link includes religious beliefs but has only been investigated in some studies. The studies found small positive relations with overall schizotypy (Lindeman and Lipsanen 2016) and unusual perceptional experiences, but only among men (White et al. 1995). Beyond the Western-Christian context, negative associations of religiosity were found in Muslim (Johnstone and Tiliopoulos 2008) and Hindu samples, especially with aspects of disorganized schizotypy (Lesmana and Tiliopoulos 2009). Apart from traditional beliefs, there is a positive association between paranormal beliefs (e.g., belief in witchcraft) and positive symptoms of schizotypy (Hergovich et al. 2008; Thalbourne 1994; Wolfradt et al. 1999).

Religious experience. Following the most prominent explanation that focuses on the religious experience-unusual experiences-continuum, many studies found a link between religious experience and schizotypy (Jackson 1997, 2001), especially to magical ideation/thinking (Breslin and Lewis 2017; Maltby and Day 2002; Unterrainer et al. 2011) and unusual perceptual experiences (Maltby and Day 2002), but also negative links to impulsivity (Breslin and Lewis 2017). Extreme religious experience, such as out-of-body experience (McCreery and Claridge 1995) and extra-sensory perception (Thalbourne and French 1995) show the same relation to schizotypy.

Public and private practice. Only a few studies measured religious practices-a dimension of religiosity that can trigger altered states of consciousness and religious experience (Demmrich et al. 2013). For example, Maltby and Day (2002), as well as Breslin and Lewis (2017), found positive relations between religious practices and schizotypy. In both studies, religious experience was surveyed in relation to religious practices that individuals can perform. In an earlier study by 
Breslin and Lewis (2015), a multidimensional measure of prayer revealed that the schizotypy subscale magical thinking was the only significant predictor of all types of prayer. Distinguishing between public and private religious practices, the frequency of private rituals was negatively related to schizotypy, whereas the frequency of temple attendance related positively in a Hindu sample (Lesmana and Tiliopoulos 2009). In a Muslim sample, on the other hand, both types of rituals related negatively to schizotypy (Johnstone and Tiliopoulos 2008). Mohr and Huguelet (2004) found a disproportionally high performance of public and private religious practices among schizophrenic patients compared to the general population. Contrarily, Tiliopoulos and Bikker (2013) did not find any differences in the frequency of public nor private practices between groups of people with high and low schizotypy. Similarly, Piedmont (2009) showed that the frequency and importance of both types of rituals and schizotypal personality disorder are unrelated when controlling for the Big Five personality traits, but joy and contentment that can be experienced during these rituals showed a low positive correlation. Beyond established religious traditions, New Age practices were related to magical ideation and a cognitive style of looseness of associations, while Christian traditional practices were not related to schizotypy characteristics (Farias et al. 2005). In conclusion, the religious practice dimension or religiosity seems to be most controversial in terms of its relation to schizotypy.

Religious orientation. Past research typically found that intrinsically religious-oriented individuals score lower on schizotypy, while extrinsically-oriented individuals show the reversed pattern, but the results are gender-specific (Maltby and Day 2002; Maltby et al. 2000). This assumption was supported and extended by Tiliopoulos and Bikker (2013), who could additionally show that high schizotypy was not only related to extrinsic religiosity, but also to high quest-scores (i.e., high religious doubts; see Batson and Schoenrade 1991). Furthermore, Joseph et al. (2002) even found that the quest was the only religious orientation related to schizotypy. In some studies, non-religious individuals are included as a control group. Day and Day and Peters (1999) could show that non-religious individuals score lower on positive (unusual experiences) as well as negative symptoms (introverted anhedonia) than members of New Religious Movements and mainstream Christianity. Similarly, Peters et al. (1999) found that non-religious people scored on average lower on delusional ideas than mainstream Christians, members of New Religious Movements, and hospitalized deluded individuals. In line with these results, Reed and Clarke (2014) found in a priming experiment that low-to-none religious individuals report less false visual perceptions of religious content than religious individuals do.

In sum, all religious dimensions show positive relations with schizotypy, mostly to positive symptoms (e.g., magical thinking, unusual perceptions), but also to negative symptoms (e.g., introverted anhedonia) and at the same time negative relations to disorganized (e.g., attentional deficiencies) and antisocial aspects (e.g., impulsiveness). In most of the studies, religious/extrinsically-oriented individuals score higher on schizotypy than highly-religious/intrinsically oriented, while non-religious individuals show the lowest levels of schizotypy. This suggests that there might be a curvilinear relation between religiosity and schizotypy on top of, or instead of, a linear relation.

An additional question is, however, whether people who are in an environment that promotes their beliefs report lower levels of schizotypy (Day and Peters 1999; Maltby and Day 2002; Mohr and Huguelet 2004; Ng 2007). Specifically, individuals who are embedded in a religious community that activates a shared religious framework-which can give a culturally-accepted (i.e., religious) meaning to bizarre, schizotypal experiences and behavior-can show lower levels of schizotypy compared to individuals who are not embedded in such a community and framework of interpretation (the prevention hypothesis). Research on the person-environment fit suggests that this might be the case. For example, Gebauer et al. (2017) found across 65 countries and millions of participants that religious individuals report higher self-esteem in religious countries but lower self-esteem in more secular countries compared to less religious people. 


\subsection{Values, Religiosity, and Schizotypy}

While previous research has explored whether gender moderates the religiosity-schizotypy link (see above), less attention has been paid to psychological moderators. For example, we believe that human values play a role in the religiosity-schizotypy association. Values are often defined as abstract ideals and guiding principles in people's life (Maio 2016; Schwartz 1992). The predominant value model in psychological research was proposed by Schwartz (1992). Schwartz found consistently across 20 countries that values can be arranged alongside two dimensions: self-transcending vs. self-enhancement values and openness vs. conservation values. The latter dimension is especially relevant to the present research. Openness values express self-direction, stimulation, and hedonism while conservation values express security, conformity, and tradition. A meta-analysis found that religiosity is mainly positively correlated with conformity and tradition values, while negatively correlated with self-direction, stimulation, and hedonism (Saroglou et al. 2004). These findings were consistent across religious denominations (Christians, Jews, Muslims) and within Christian samples (e.g., Spanish Roman Catholics, Dutch Calvinist protestants, Greek Orthodox; see also Schwartz and Huismans 1995). Tradition and conformity share a "single basic motivational goal-submission of self to external expectations", although conformity emphasizes the subordination towards other people, whereas tradition the subordination towards "transcendent authorities and past ideas" (Schwartz and Huismans 1995, p. 89). Hence, both are linked to aspects of religiosity.

While most previous research has measured religiosity unidimensionally, some more recent research found that the dimensions of religiosity are differently associated with the same value type. For example, Gennerich and Huber (2006) found that religious pluralism and reflexivity are positively correlated with the dimension openness vs. conservation, while the other religiosity dimensions were, as expected, negatively correlated with this value dimension (e.g., worship attendance, dualism, exclusivism). Somewhat similar, Stein (2016) found that most dimensions of religiosity correlated positively with tradition values (e.g., intellect, public religious practice), but private religious practice was uncorrelated in large samples across several religious denominations. However, unlike other research, Stein (2016) reported that all other nine value types were uncorrelated with the dimensions of religiosity.

In contrast, only one study investigated the relations between values and schizotypy to the best of our knowledge. Hanel and Wolfradt (2016) found that cognitive disorganization was weakly positively correlated with hedonism and negatively with security. Similarly, impulsive disorganization was positively correlated to all openness values and negatively with all conservation values. Further, introverted anhedonia was weakly negatively correlated with stimulation and hedonism but positively with security and tradition.

Sparse previous research found that the relations of values with other variables can be moderated by contextual factors (e.g., Boer and Fischer 2013) and by other factors such as identification. For example, openness vs. conservation values predicted suggestion-making in an organizational context (e.g., suggestions how the work can be improved), but this relation was higher for those employees who identified themselves stronger with their organization (Lipponen et al. 2008). This suggests that values can enhance or soften the impact of identification on suggestion-making.

Related to the present research, we hypothesize that if religious beliefs and values align, this will have a positive effect on well-being (here: lower schizotypy scores), because beliefs and values are congruent (schizotypy is negatively related to various measures of well-being; Farias et al. 2013; Hanel and Wolfradt 2016). This prediction is an extension of Higgins's (1987) self-discrepancy theory, which postulates that there are three versions of the self: an actual self (the attributes that you believe you actually possess), an ideal self (attributes you wish to possess), and an ought self (attributes you believe other people want you to possess). Higgins postulated and found that discrepancies between the actual- and ought-self as well as between the actual- and ideal-self are associated with higher levels of anxiety, stress, guilt, or depression. We consider both religiosity and values as part of the ideal-self. 


\subsection{The Present Research}

In the present study, we used for the first time Huber's (2003) approach of Centrality of Religiosity to investigate the relations between religiosity and schizotypy. Huber's model encompasses five dimensions of religiosity and Centrality of Religiosity in life. Building on previous research, which measured religiosity mainly as a one- or two-dimensional construct, we hypothesize that:

1. There are positive correlations of all religiosity dimensions with unusual experiences and introverted anhedonia. Furthermore, we expect negative relations of all religiosity dimensions with disorganization and impulsive nonconformity.

2. Highly religious individuals score lower on schizotypy than religious individuals. Non-religious individuals should display the lowest schizotypy scores, implying quadratic relations.

3. The association between religiosity and schizotypy is moderated by religious affiliation. Based on the prevention hypothesis of schizotypy and the person-environment fit literature discussed above, we expect that the link between religiosity and schizotypy is only positive for individuals who are not religiously affiliated.

4. Regarding the relation between religiosity, schizotypy, and values, we expect that values moderate the relations of schizotypy with overall religiosity: Religious people who place more importance on conformity and tradition, score lower on schizotypy than religious people who value conformity and tradition less.

Additionally, we assume that at least some of the correlations are related to age (Breslin and Lewis 2015, 2017), gender (Maltby and Day 2002; White et al. 1995), and can be confounded by social desirability (Diduca and Joseph 1997; Joseph et al. 2002). Finally, a strength of this approach is the simultaneous consideration of dimensions of religiosity that allows us to explore unique religious predictors of schizotypy.

\section{Materials and Methods}

\subsection{Participants and Procedure}

The participants were 189 students $\left(M_{\text {age }}=23.47, S D_{\text {age }}=6.68 ; 127\right.$ women, 61 men $)$ who completed the survey in a classroom setting during lecture time at a university in East-Germany. The students studied various subjects (e.g., history, mathematics), but all were teacher trainees. Seventy-seven participants were not part of a religious community and 112 were part of a community (93 Protestant, 6 Catholic, 14 other). A sample size of 189 participants is large enough to detect effect sizes of $r=0.20$ with a power of 0.80 .

\subsection{Materials}

Religiosity was measured with the Centrality of Religiosity Scale by Huber (2003; Huber and Huber 2012). We used its 15-items version which measures the five dimensions of religiosity: Intellect (e.g., "How often do you think about religious issues"), religious ideology (e.g., "To what extent do you believe that God or something divine exists?"), religious experience (e.g., "How often do you experience situation in which you have the feeling that God or something divine is present?"), public religious practice (e.g., "How often do you take part in religious services?"), and private religious practice (e.g., "How often do you pray?"). Responses were mainly given on a 5-point scale. Numerous previous studies found that the scale is a very reliable and valid measure of religiosity. Indeed, in our sample, internal consistencies for all five subscales and the overall scale were also very high (Cronbach's $\alpha s=0.89-0.97$; Table 1). 
Table 1. Descriptive statistics, internal consistencies (main diagonal), zero-order correlations (below diagonal), and partial correlations (above diagonal).

\begin{tabular}{|c|c|c|c|c|c|c|c|c|c|c|c|c|c|c|c|c|c|c|c|}
\hline & $\mathbf{M}$ & SD & 1 & 2 & 3 & 4 & 5 & 6 & 7 & 8 & 9 & 10 & 11 & 12 & 13 & 14 & 15 & 16 & 17 \\
\hline 1. Overall Religiosity & 2.22 & 1.34 & 0.97 & 0.94 & 0.83 & 0.96 & 0.91 & 0.89 & & & 0.17 & 0.56 & & & 0.08 & 0.00 & 0.09 & -0.15 & 0.01 \\
\hline 2. Public religious practice & 2.13 & 1.59 & 0.94 & 0.94 & 0.76 & 0.89 & 0.78 & 0.76 & & & 0.18 & 0.53 & & & 0.00 & -0.01 & 0.05 & -0.20 & -0.06 \\
\hline 3. Intellect (interest in religiosity) & 2.22 & 1.08 & 0.85 & 0.79 & 0.89 & 0.49 & 0.54 & 0.50 & & & -0.01 & 0.35 & & & 0.06 & 0.05 & -0.01 & 0.00 & 0.04 \\
\hline 4. Private religious practice & 2.62 & 1.99 & 0.96 & 0.91 & 0.74 & 0.89 & 0.73 & 0.74 & & & 0.06 & 0.32 & & & 0.04 & 0.00 & 0.15 & -0.10 & 0.04 \\
\hline 5. Religious ideology & 2.66 & 1.39 & 0.92 & 0.81 & 0.74 & 0.86 & 0.94 & 0.71 & & & 0.09 & 0.43 & & & 0.18 & 0.03 & 0.09 & -0.08 & 0.10 \\
\hline 6. Religious experience & 1.46 & 1.21 & 0.91 & 0.79 & 0.71 & 0.86 & 0.83 & 0.94 & & & 0.10 & 0.36 & & & 0.19 & 0.07 & 0.15 & 0.04 & 0.18 \\
\hline 7. Age & 23.47 & 6.68 & 0.07 & 0.11 & 0.14 & 0.06 & 0.02 & 0.02 & & & & & & & & & & & \\
\hline 8. Gender (1: $f, 2: m)$ & 1.32 & 0.67 & -0.10 & -0.07 & -0.03 & -0.10 & -0.14 & -0.09 & 0.14 & & & & & & & & & & \\
\hline 9. Conformity values & 3.85 & 0.92 & 0.27 & 0.26 & 0.18 & 0.25 & 0.26 & 0.28 & -0.15 & -0.23 & 0.67 & 0.52 & & & 0.00 & 0.01 & 0.08 & -0.24 & -0.05 \\
\hline 10. Tradition values & 3.38 & 0.89 & 0.59 & 0.56 & 0.54 & 0.52 & 0.57 & 0.53 & 0.04 & -0.13 & 0.57 & 0.47 & & & 0.15 & 0.08 & 0.03 & -0.18 & 0.04 \\
\hline 11. SD: impression management & 4.20 & 0.69 & 0.38 & 0.34 & 0.32 & 0.34 & 0.37 & 0.36 & 0.05 & -0.03 & 0.32 & 0.25 & 0.59 & & & & & & \\
\hline 12. SD: self-deception & 3.79 & 0.95 & 0.04 & 0.06 & 0.08 & 0.12 & 0.06 & 0.14 & 0.01 & 0.08 & -0.01 & 0.04 & 0.10 & 0.64 & & & & & \\
\hline 13. SZ: Unusual experiences & 0.32 & 0.20 & 0.03 & -0.04 & 0.01 & -0.01 & 0.11 & 0.09 & -0.10 & -0.03 & -0.01 & 0.11 & -0.09 & -0.07 & 0.65 & 0.30 & -0.12 & 0.34 & 0.64 \\
\hline 14. SZ: Cognitive disorganization & 0.40 & 0.22 & -0.02 & -0.03 & 0.00 & -0.04 & 0.01 & -0.01 & -0.11 & -0.01 & 0.05 & 0.06 & -0.02 & -0.39 & 0.37 & 0.65 & 0.16 & 0.38 & 0.74 \\
\hline 15. SZ: Introverted anhedonia & 0.16 & 0.17 & 0.08 & 0.05 & 0.01 & 0.11 & 0.08 & 0.11 & 0.04 & 0.17 & 0.08 & 0.04 & 0.05 & -0.25 & -0.08 & 0.21 & 0.60 & 0.06 & 0.41 \\
\hline 16. SZ: Impulsive nonconformity & 0.34 & 0.19 & -0.29 & -0.32 & -0.21 & -0.29 & -0.25 & -0.21 & -0.04 & 0.04 & -0.36 & -0.31 & -0.42 & -0.24 & 0.37 & 0.37 & 0.05 & 0.56 & 0.70 \\
\hline 17. Overall SZ & 0.30 & 0.13 & -0.08 & -0.14 & -0.07 & -0.09 & -0.02 & -0.01 & -0.09 & 0.06 & -0.09 & -0.04 & -0.19 & -0.37 & 0.66 & 0.78 & 0.42 & 0.70 & 0.74 \\
\hline
\end{tabular}

Note. Partial correlations above main diagonal (top right part of the correlation matrix): Controlled for age, gender, and social desirability. SD: Social desirability; SZ: Schizotypy.
Cronbach's alphas are in main diagonal, if applicable. All $r s \geq 0.15$ are significant at $\alpha=0.05, r s \geq 0.19$ are significant at $\alpha=0.01$, and all $r s \geq 0.24$ are significant at $\alpha=0.001$ (all two-tailed). 
Conformity and tradition values were each measured with four items of the Portrait Value Questionnaires (Schwartz et al. 2001). Participants were instructed to rate how similar they are to a hypothetical other person. Example items include "The person believes that people should do what they're told. The person thinks people should follow rules at all times, even when no-one is watching." (conformity) and "The person thinks it is best to do things in traditional ways. It is important to the person to keep up the customs s/he has learned" (tradition). Responses were given on a scale from 1 (very different) to 6 (very similar). The internal consistency of conformity was satisfactory $(\alpha=0.67)$, but, in line with previous research, low for tradition $(\alpha=0.47$; for example, in the validation paper of the Portrait Value Questionnaire, (Schwartz et al. 2001), report an $\alpha$ of only 0.37 for tradition and an $\alpha$ of 0.48 for conformity, suggesting that the quality of our data is high).

Social desirability was measured with the two-factor social-desirable scale by Paulhus (1984) in its German translation (Musch et al. 2002). The two factors are self-deception (e.g., "I already doubted my sexual adequacy") and impression management (e.g., "I took already once sick-leave from work or school, without being sick"). Responses were given on a 7-point scale ranging from 1 (completely disagree) to 7 (completely agree). The internal consistencies were satisfactory (see Table 1).

Schizotypy was measured with the Oxford-Liverpool Inventory of Feelings and Experiences (Mason et al. 2005). This 43-item scale measures four factors of schizotypy: Unusual experiences (e.g., "Do you think that you could learn to read other's minds if you wanted to?"), cognitive disorganization (e.g., "Are you easily distracted from work by daydreams?"), introverted anhedonia (e.g., "Have you often felt uncomfortable when your friends touch you?"), and impulsive nonconformity (e.g., "Do you ever have the urge to break or smash things?"). Answers were given on a two-point Yes-No scale. Internal consistencies were satisfactory (Table 1).

Finally, the questionnaire asked for age, gender, and religious affiliation. ${ }^{1}$

\section{Results}

Because most previous research found gender differences in the relations between religiosity and schizotypy, we tested in a first step whether gender would moderate the religiosity—schizotypy relations. For this, we performed 5 (religious dimensions) $\times 4$ (schizotypy dimensions) moderated regressions with gender as the moderator, the religious dimensions as the predictor, and the dimensions of schizotypy as the dependent variable. However, none of the 20 interaction terms reached statistical significance (all $p s>0.15$ ), suggesting that there were no gender differences for the religion-schizotypy associations. We therefore collapsed the data across gender. ${ }^{2}$

We tested Hypothesis 1 through a series of zero-order and partial correlation. Recall that Hypothesis 1 stated that there are positive correlations between the Centrality of Religiosity dimensions and unusual experiences and introverted anhedonia as well as negative correlations with disorganization and impulsive nonconformity. Zero-order correlations revealed negative relations between all five dimensions of religiosity as well as overall religiosity with impulsive nonconformity, which is consistent with our predictions. However, contrary to our predictions, the remaining three schizotypy dimensions were not significantly correlated with religiosity. After controlling for age, gender, and social desirability, only public religious practices and overall religiosity remained significantly correlated with impulsive nonconformity. Interestingly, through adding the control variables, religious experience was then positively correlated with unusual experiences.

1 We made the data and R-code available on the Open Science Framework: https://osf.io/grv4f/?view_only= 51c8d353d2054be086a5bd5026e66c8c.

2 Each of the four hypotheses was tested with a set of at least 20 tests. To reduce the likelihood of the type-I error-to erroneously conclude that there is an effect-we adjusted the alpha level to 0.004 . In other words, we will only consider effects as statistically significant, if the $p$-value is smaller than 0.004 . Corrections for multiple comparisons are often somewhat arbitrary with the number of tests one needs to control for the most difficult to determine. We report the exact $p$-values for many of our findings because we acknowledge that other researchers might prefer a more conservative or more liberal alpha level. 
However, the non-significant correlations only suggest that there are no linear relations between Centrality of Religiosity and schizotypy. Hypothesis 2 postulates that the religion-schizotypy relations are quadratic. We tested Hypothesis 2 using a series of 5 (religious dimensions) $\times 4$ (schizotypy dimensions) regression analyses with the linear and quadratic term of the religious dimensions as predictors. Only the quadratic term of private religious practice was predicted significantly over the linear term unusual experiences, $b=-0.02, S E=0.006, p=0.0015$. This quadratic association is displayed in Figure 1 and remains significant after controlling for multiple comparisons. Note that treating religiosity as a continuous variable rather than transforming it to a categorical variable (e.g., non-religious, religious, and highly-religious people, cf. Huber and Huber 2012) is statistically superior because we do not lose meaningful variance by treating all non-religious people the same, but allowing them to vary (this criticism is purely statistical; there might be theoretical reasons to divide people into the three categories).

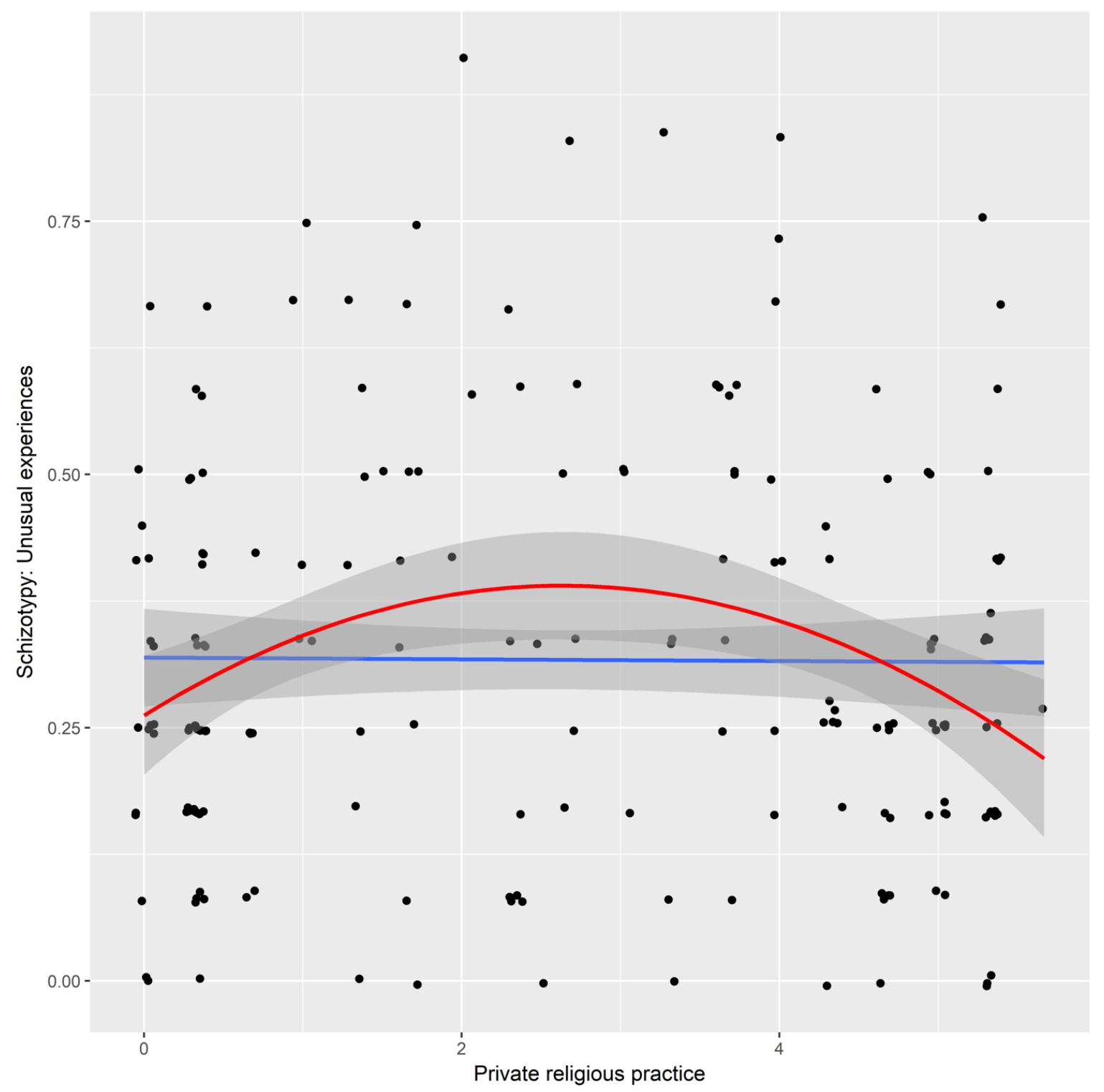

Figure 1. Scatterplot with linear (blue line) and quadratic (red line) trend lines. The grey areas around the lines represent the $95 \%$ confidence interval.

To test Hypothesis 3-religious affiliation moderates the religiosity-schizotypy link-we performed again a series of 5 (religious dimensions) $\times 4$ (schizotypy dimensions) regression 
analyses with religious affiliation as a mediator variable. Four out of the 20 analyses reached statistical significance at $\alpha=0.004$. For three of these, impulsive nonconformity was the dependent variable. Specifically, affiliation to a religious community moderated the relations between impulsive nonconformity and private religious practice, $b=-0.08, S E=0.02, p=0.0007$; religious ideology, $b=-0.13, S E=0.03, p=0.00001$; and religious experience, $b=-0.11, S E=0.03, p=0.0007$. Further, religious affiliation moderated the relation between unusual experiences and private religious practice, $b=-0.08, S E=0.02, p=0.002$. Simple slope analyses revealed that the correlation between religiosity and schizotypy was, as predicted, positive for people who are not in a religious community but negative for those who are (Figure 2).
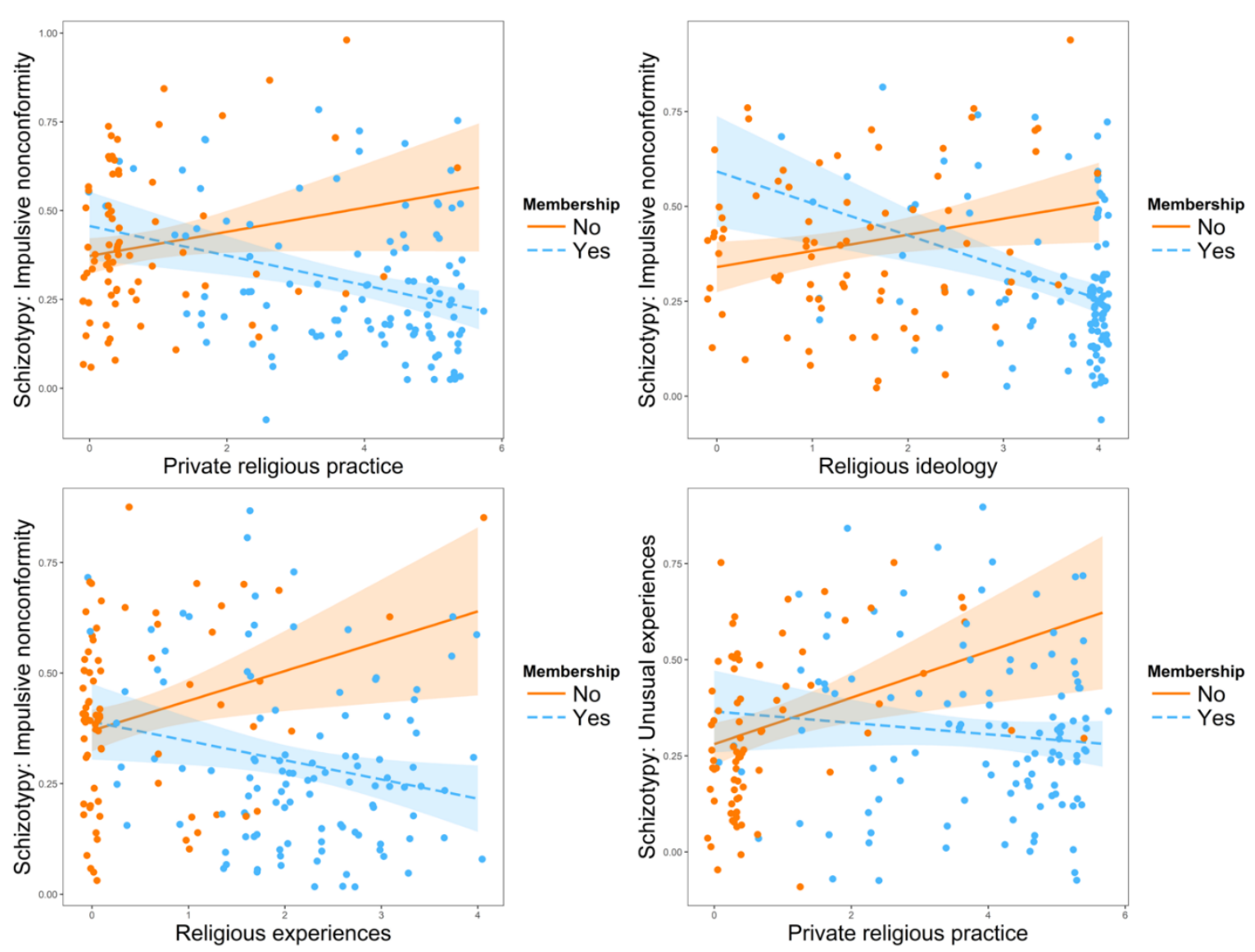

Figure 2. Associations between religiosity and schizotypy by membership in a religious community. The band represents the $95 \%$ confidence interval.

Prior to testing Hypothesis 4, we investigated whether the correlations of values with religiosity and schizotypy would replicate previous research, further ensuring the quality of our data. Indeed, we found that conformity and tradition values correlated negatively with impulsive nonconformity, which is in line with the findings of Hanel and Wolfradt (2016). Further, tradition was most strongly associated with all religious dimensions, replicating most previous research on religiosity and values (e.g., Saroglou et al. 2004; Stein 2016).

We tested Hypothesis 4-values moderate the relations of schizotypy with overall religiosity-in a series of 2 (values: conformity and tradition) $\times 4$ (schizotypy dimensions) moderated regressions, with overall religiosity as a predictor. ${ }^{3}$ Conformity interacted significantly with religiosity in predicting

3 We used overall religiosity as a predictor rather than the five separate dimensions to reduce the number of tests (it would have been 40 moderated regressions rather than 8 otherwise). 
unusual experiences $(b=-0.03, S E=0.01, p=0.02)$ and cognitive disorganization $(b=-0.03, S E=0.01$, $p=0.047)$. The pattern of results was the same for both schizotypy dimensions. As predicted, the relations between religiosity and the two schizotypy dimensions were negative for people who valued conformity more and positive for people who valued it less. However, given that we performed eight tests, none of these findings survived after controlling for multiple comparisons, indicating that conformity and tradition do not moderate the religion-schizotypy dimensions.

Finally, we explored which of the five dimensions of Centrality of Religiosity was best in predicting schizotypy. Because Centrality of Religiosity was only significantly correlated with impulsive nonconformity, we focused on this schizotypy dimension. Multiple regression analyses revealed that public religious practice was the only significant predictor of impulsive nonconformity (Table 2).

Table 2. Multiple regression analyses: Religiosity dimensions predicting impulsive nonconformity.

\begin{tabular}{cc}
\hline & $b s$ \\
\hline Intellect & $0.01(0.02)$ \\
Religious ideology & $-0.01(0.02)$ \\
Religious experience & $0.01(0.02)$ \\
Public religious practice & $-0.05(0.02)^{*}$ \\
Private religious practice & $-0.01(0.02)$ \\
Adjusted $R^{2}$ & $0.08^{* * *}$ \\
$F$ & 4.52 \\
\hline
\end{tabular}

Note. The adjusted $R^{2}$ is adjusted for the number of predictors. Standard errors are in brackets. ${ }^{*} p \leq 0.05,{ }^{* * *} p<0.001$.

\section{Discussion}

The aim of the present study was fourfold. First, we tested how the five dimensions of Huber's (2003) model of religiosity are associated with the four dimensions of schizotypy. All dimensions of religiosity and overall Centrality of Religiosity correlated negatively and significantly with impulsive nonconformity. Second, after controlling for potential confounding variables, the relation between overall religiosity as well as public religious practice on the one side and impulsive nonconformity on the other side remained stable. Third, in the regression analysis, impulsive nonconformity was significantly predicted by public religious practice as the unique predictor; however, the share of explained variance was very small. Impulsive nonconformity, which is related to violent and reckless behaviors, can be suppressed by religious rituals as they can channel antisocial tendencies and regulate negative emotions (Demmrich and Wolfradt 2018). However, in contrast to previous research (e.g., Maltby and Day 2002; White et al. 1995), we did not find that gender moderated the effect between the dimensions of religiosity and schizotypy.

Further, the pattern of association between religiosity and impulsive nonconformity was less pronounced when we controlled for age, gender, and social desirability. This reduced association might arise because of the positive correlations of the social desirability dimension impression management with all dimensions of religiosity and some dimensions of schizotypy, suggesting some shared variance between the three sets of constructs (Diduca and Joseph 1997; Joseph et al. 2002). More research is needed to establish whether these correlations suggest some response biases in religiosity and schizotypy or whether they share some attribute underlying these three sets of constructs (see the style vs. substance debate, e.g., Smith and Ellingson 2002).

Second, we tested whether the relations between the dimensions of religiosity and schizotypy are quadratic, with non-religious and highly religious people being less schizotypal. However, of the 20 possible quadratic trends, only one was statistically significant after correcting for multiple comparisons: Participants who scored modest on the private religious practice dimension also reported more unusual experiences. This result is in line with our prediction and previous studies which found that non-religious individuals display the lowest levels of schizotypy (Day and Peters 1999; Peters et al. 1999; Reed and Clarke 2014). 
Further, because in Huber's (2003) approach, high religiosity corresponds to intrinsic religiosity and moderate religiosity corresponds to extrinsic religiosity, this finding replicates similar previous research (Maltby et al. 2000; Maltby and Day 2002; Tiliopoulos and Bikker 2013). However, our study adds further clarification to the most controversial religiosity-schizotypy link that refers to the dimension of religious practice. The associations between impulsive nonconformity with both private religious practices and public rituals are similar: The frequent performance and high importance of private prayer and public ritual practice can channel antisocial, nonconforming tendencies, and impulsiveness within a religious frame, and thereby seem to have a buffering function.

This result of a negative link between rituals and schizotypal aspects confirms earlier studies in which private and public religious practice were measured separately (Lesmana and Tiliopoulos 2009; Johnstone and Tiliopoulos 2008) and contradicts findings that measured both ritual dimensions not clear-cut (Piedmont 2009; Tiliopoulos and Bikker 2013). However, while the former studies only measured frequency for both ritual dimensions separately, the latter studies measured the importance of those rituals but neglected the public versus private differentiation. To shed more light on this controversial link, future studies should intersect both approaches, by measuring frequency as well as the importance of private and public rituals separately. Additionally, the other 19 non-significant tests of our quadratic trend analyses can either suggest that religiosity is linearly (if at all) associated with the dimensions of schizotypy or that our sample of 189 participants was too small to detect potentially minor effects.

Third, in line with our predictions, we found that associations between the dimensions of religiosity and schizotypy were positive for participants who were not a member of a religious community but negative for those who were members. Although the emphasis in explaining the religiosity-schizotypy link relies on experiential explanations (Jackson 1997, 2001; James [1902] 1928; Mohr and Huguelet 2004; Peters 2001; Smith et al. 2009), implying positive links between the two concepts, three out of four significant tests were reliable for negative relations to impulsive nonconformity among the religiously affiliated. This supports the alternative explanation of the prevention hypothesis (Lesmana and Tiliopoulos 2009; Maltby and Day 2002; Wulff 1997) which implies a negative relation as schizotypal individuals use religious explanations for bizarre experiences that decrease emotional, cognitive, and notably behavioral arousal (see Mohr and Huguelet 2004; Ng 2007). Our results suggest that this negative correlation between religiosity and schizotypy is stronger for individuals who are embedded in a religious community that shares a culturally-accepted (religious) interpretation of such bizarre behaviors. This is also in line with the theory of person-environment fit, which predicts higher well-being (operationalized through self-esteem) for religious individuals in religious environments and lower well-being for religious individuals in non-religious environments (e.g., Gebauer et al. 2017). Interestingly, impulsive nonconformity is probably the schizotypal dimension that is most easily observable by others and suggests that religious communities affect mainly individual behavior rather than thoughts (e.g., cognitive disorganization) or experiences (e.g., unusual experiences).

Fourth, contrary to our expectations, conformity and tradition values did not moderate the associations between religiosity and schizotypy. There are at least two potential explanations for this non-significant finding. Firstly, if our initial prediction is correct and the alignment of values with religiosity is associated with higher well-being, schizotypy might tap into a different type of well-being that is unrelated to this congruence of religiosity and values. Instead, more positive estimators of well-being such as subjective well-being, self-esteem, or satisfaction with life might be more relevant. Secondly, our initial prediction may have been wrong and whether religiosity and values align is irrelevant to someone's well-being. This might be because religiosity, especially the dimensions of Huber's (2003) Centrality of Religiosity model, might already be heavily value-laden so that responses to abstract values (Schwartz 1992) might not be relevant. Likewise, even conformity and tradition value types are broad constructs that tap into values that are important beyond religiosity (e.g., being 
humble can also be important in a professional setting or at school). Future research is needed to test these predictions.

However, in line with previous research (e.g., Hanel and Wolfradt 2016; Saroglou et al. 2004), we found that conformity and tradition values were negatively associated with impulsive nonconformity and that tradition values were strongly associated with religiosity, suggesting that failing to support Hypothesis 4 is unrelated to the reliability or validity issues of the used scales.

\subsection{Limitations}

While our sample size was large enough to detect small-to-medium-size effects, it consists of students and is therefore not representative. Indeed, previous research suggests that it can be problematic to generalize from student samples to the public (Hanel and Vione 2016). Thus, our findings should be understood as preliminary and need to be replicated within larger and more representative samples, ideally also in non-Western countries.

A great asset to the current state of research was the use of Huber's (2003) Centrality of Religiosity Scale in our study. But at the same time, we did not measure other forms and aspects of religiosity that might be associated with schizotypy. One of them is quest, which is a form of religiosity in which religious doubts are prevalent and appreciated (Batson and Schoenrade 1991) that shows positive relations to schizotypy (Joseph et al. 2002; Tiliopoulos and Bikker 2013). We further recommend that future studies split extrinsic religiosity into extrinsic-social (i.e., religion is practiced for social gains) and extrinsic-personal (i.e., religion is practiced for personal gains; Gorsuch and McPherson 1989) as Maltby et al. (2000) found that extrinsic-social religiosity serves as a pathogenic factor in the development of positive schizotypal symptoms.

Thirdly, further studies should include the individual's God image and attachment to God. Generally, the God image often serves as a moderator between religiosity and well-being (e.g., Demmrich etal. 2013) and specifically, a positive God image protects from schizotypy (Tiliopoulos and Bikker 2013). Similarly, Hancock and Tiliopoulos (2010) found that an anxious, but not avoidant attachment to God predicts schizotypy, and Piedmont (2009) found that the schizotypal personality disorder related to a religious crisis is associated with the feeling of being punished by God. Therefore, an anxious attachment to God and/or a negative God image might heighten the awareness to aspects of everyday situations that are interpreted as divine signs, which in turn increases the possibility to develop schizotypal personality disorder or even schizophrenia.

\subsection{Implications}

Our first implication for mental health practitioners is in line with previous research on the religiosity-schizotypy link that uncovered intrinsic religiosity as a salutogenic factor and extrinsic religiosity as a pathogenic factor (Maltby and Day 2002; Wulff 1997). Using the concept of Huber (2003), in which high religiosity equals intrinsic religiosity and moderate religiosity equals extrinsic religiosity, another indicator for a protective form of religiosity is the Centrality of Religiosity in the individual's life. Only if religiosity has consequences for life, that is, religiosity influences other non-religious aspects of the individual's life and therefore contributes to a rich religious experience and behavior (Huber et al. 2011), can it potentially prevent the development of schizotypal aspects, especially unusual experiences.

Additionally, our findings suggest that religious individuals benefit from being affiliated with a religious community. This is an important finding for mental health practitioners who might want to advise their religious clients, if applicable, to join a religious community because it provides norms and buffers for potential forms of personality and schizophrenic disorders (Day and Peters 1999; $\mathrm{Ng}$ 2007). This advice is sometimes seen as ethically controversial (Mohr and Huguelet 2004) and can be extended to joining any other social group that offers a culturally-accepted interpretation framework for schizotypal aspects and rituals. Especially, rituals can channel antisocial behavioral tendencies, such as impulsiveness, poor self-control, and mood swings (for the emotion-regulating potential of rituals 
beyond established religions see Demmrich and Wolfradt 2018). Not being part of an environment in which someone fits in might also explain why spiritual but not religious people, a population that is at least in the USA growing, reports higher levels of schizotypy compared to non-religious and religious individuals (Willard and Norenzayan 2017). The population of spiritual but not religious people presumably does not have as many established communities as religious people, which may help to buffer against potential negative side-effects of religiosity or spirituality.

\section{Conclusions}

In the present research, we found negative small-to-medium-sized correlations between all five dimensions of religiosity and the schizotypy dimension impulsive nonconformity, but no reliable associations with the other three dimensions of schizotypy. Some of these associations were moderated by religious affiliation: Religiosity and schizotypy correlated positively among the religiously unaffiliated, but negatively among members of religious communities, suggesting that such membership has a positive impact on the well-being of religious people. Overall, our findings suggest that religious people who are not part of a religious community might want to consider joining such a group of like-minded people. Taking together the central findings, religiosity, especially rituals and religious affiliation, relates negatively to schizotypal dimensions, whereby the dimension of impulsive nonconformity plays a central role. Returning to our introduction example, we can ask ourselves why Abraham did not kill his son while the woman with untreated schizophrenia did kill her daughter (Saha et al. 2015). From a psychological perspective, we can only speculate that Abraham performed religious practices quite often (e.g., Genesis 18, 23; Genesis 20, 17a) and was, as the founder of a religious community, embedded into a religious framework that prevented him from engaging into this kind of impulsive, nonconforming, and anti-social behavior.

Author Contributions: Conceptualization: U.W.; Methodology: U.W.; Software: P.H.P.H., S.D., U.W.; Validation: P.H.P.H., S.D., U.W.; Formal Analysis: P.H.P.H., S.D., U.W.; Investigation: P.H.P.H., S.D., U.W.; Resources: U.W.; Data Curation: P.H.P.H., U.W.; Writing-Original Draft Preparation: P.H.P.H., S.D., U.W.; Writing一Review \& Editing: P.H.P.H., S.D., U.W.; Visualization, P.H.P.H.; Project Administration: U.W.

Funding: This research received no external funding.

Conflicts of Interest: The authors declare no conflict of interest.

\section{References}

Allport, Gordon W., and J. Michael Ross. 1967. Personal religious orientation and prejudice. Journal of Personality and Social Psychology 5: 432-43. [CrossRef]

Batson, C. Daniel, and Patricia A. Schoenrade. 1991. Measuring religion as quest: 1) Validity concerns. Journal for the Scientific Study of Religion 30: 416-29. [CrossRef]

Boer, Diana, and Ronald Fischer. 2013. How and when do personal values guide our attitudes and sociality? Explaining cross-cultural variability in attitude-value linkages. Psychological Bulletin 139: 1113-47. [CrossRef]

Breslin, Michael J., and Christopher Alan Lewis. 2015. Schizotypy and religiosity: The magic of prayer. Archive for the Psychology of Religion 37: 84-97. [CrossRef]

Breslin, Michael J., and Christopher Alan Lewis. 2017. Examining the relationship between schizotypy and religious experience among Irish adults. Mental Health, Religion \& Culture 20: 398-404. [CrossRef]

Claridge, Gordon. 1994. Single indicator of risk for schizophrenia: Probable fact or likely myth? Schizophrenia Bulletin 20: 151-68. [CrossRef] [PubMed]

Claridge, Gordon, Charles McCreery, Oliver Mason, Richard Bentall, Godfrey Boyle, Pauline Slade, and David Popplewell. 1996. The factor structure of 'schizotypal' traits: A large replication study. British Journal of Clinical Psychology 35: 103-15. [CrossRef] [PubMed]

Day, Samantha, and Emmanuelle Peters. 1999. The incidence of schizotypy in new religious movements. Personality and Individual Differences 27: 55-67. [CrossRef]

Dein, Simon, and Roland Littlewood. 2011. Religion and psychosis: A common evolutionary trajectory? Transcultural Psychiatry 48: 318-35. [CrossRef] [PubMed] 
Demmrich, Sarah, and Uwe Wolfradt. 2018. Personal rituals in adolescence: Their role in emotion regulation and identity formation. Journal of Empirical Theology 31: 217-38. [CrossRef]

Demmrich, Sarah, Uwe Wolfradt, and Michael Domsgen. 2013. Dissociation in religion and spirituality: God images and religious rituals in the context of dissociative experiences among a sample of German adults. Journal of Empirical Theology 26: 229-41. [CrossRef]

Diduca, Deborah, and Stephen Joseph. 1997. Schizotypal traits and dimensions of religiosity. British Journal of Clinical Psychology 36: 635-38. [CrossRef] [PubMed]

Farias, Miguel, Gordon Claridge, and Mansur Lalljee. 2005. Personality and cognitive predictors of New Age practices and beliefs. Personality and Individual Differences 39: 979-89. [CrossRef]

Farias, Miguel, Raphael Underwood, and Gordon Claridge. 2013. Unusual but sound minds: Mental health indicators in spiritual individuals. British Journal of Psychology 104: 364-81. [CrossRef] [PubMed]

Fonseca-Pedrero, Eduardo, José Muñiz, Serafín Lemos-Giráldez, Edu García-Cueto, Álvarez Campillo-Álvarez, and Ursula Villazón García. 2007. Multidimensionality of schizotypy under review. Papeles del Psicólogo 28: 117-26.

Gebauer, Jochen E., Constantine Sedikides, Felix D. Schönbrodt, Wiebke Bleidorn, Peter J. Rentfrow, Jonathan Potter, and Samuel D. Gosling. 2017. The religiosity as social value hypothesis: A multi-method replication and extension across 65 countries and three levels of spatial aggregation. Journal of Personality and Social Psychology 113: 18-39. [CrossRef]

Gennerich, Carsten, and Stefan Huber. 2006. Value priorities and content of religiosity: New research perspectives. Archive for the Psychology of Religion 28: 253-68. [CrossRef]

Gorsuch, Richard L., and Susan E. McPherson. 1989. Intrinsic/extrinsic measurement: I/E-revised and single-item scales. Journal for the Scientific Study of Religion 28: 348-54. [CrossRef]

Hancock, Lisa, and Niko Tiliopoulos. 2010. Religious attachment dimensions and schizotypal personality traits. Mental Health, Religion \& Culture 13: 261-65. [CrossRef]

Hanel, Paul H. P., and Katia C. Vione. 2016. Do student samples provide an accurate estimate of the general public? PLoS ONE 11: e0168354. [CrossRef]

Hanel, Paul H. P., and Uwe Wolfradt. 2016. The 'dark side' of personal values: Relations to clinical constructs and their implications. Personality and Individual Differences 97: 140-45. [CrossRef]

Hergovich, Andreas, Reinhard Schott, and Martin Arendasy. 2008. On the relationship between paranormal belief and schizotypy among adolescents. Personality and Individual Differences 45: 119-25. [CrossRef]

Hewitt, J. K., and Gordon Claridge. 1989. The factor structure of schizotypy in a normal population. Personality and Individual Differences 10: 323-29. [CrossRef]

Higgins, E. Tory. 1987. Self-discrepancy: A theory relating self and affect. Psychological Review 94: 319-40. [CrossRef] [PubMed]

Horrobin, D. F. 1998. Schizophrenia: the illness that made us human. Medical Hypotheses 50: 269-88. [CrossRef]

Huber, Stefan. 2003. Zentralität und Inhalt: Ein Neues Multidimensionales Messmodell der Religiosität [Centrality and Content: A New Multidimensional Measurement Model of Religiosity]. Opladen: Leske\&Budrich.

Huber, Stefan, and Odilo W. Huber. 2012. The Centrality of Religiosity Scale (CRS). Religions 3: 710-24. [CrossRef]

Huber, Stefan, Mathias Allemand, and Odilo W. Huber. 2011. Forgiveness by God and human forgivingness: The centrality of the religiosity makes the difference. Archive for the Psychology of Religion 33: 115-34. [CrossRef]

Jackson, Michael. 1997. Benign schizotypy? The case of spiritual experience. In Schizotypy. Implications for Illness and Health. Edited by G. Claridge. New York: Oxford University Press, pp. 227-50.

Jackson, Michael. 2001. Psychotic and spiritual experience: A case study comparison. In Psychosis and Spirituality. Exploring the New Frontier. Edited by I. Clarke. Philadelphia: Whurr, pp. 165-90.

James, William. 1928. The Varieties of Religious Experience: A Study in Human Nature. New York: Longmans, Green \& Co. First published 1902.

Johnstone, Jennifer, and Niko Tiliopoulos. 2008. Exploring the relationship between schizotypal personality traits and religious attitude in an international Muslim sample. Archive for the Psychology of Religion 30: 241-54. [CrossRef]

Joseph, Stephen, David Smith, and Deborah Diduca. 2002. Religious orientation and its association with personality, schizotypal traits and manic-depressive experiences. Mental Health, Religion $\mathcal{E}$ Culture 5: 73-81. [CrossRef] 
Kerns, John G. 2006. Schizotypy facets, cognitive control, and emotion. Journal of Abnormal Psychology 115: 418-27. [CrossRef]

Lesmana, Cokorde B., and Niko Tiliopoulos. 2009. Schizotypal personality traits and attitudes towards Hinduism among Balinese Hindus. Mental Health, Religion \& Culture 12: 773-85. [CrossRef]

Lindeman, Marjaana, and Jari Lipsanen. 2016. Diverse cognitive profiles of religious believers and nonbelievers. The International Journal for the Psychology of Religion 26: 185-92. [CrossRef]

Lipponen, Jukka, Anat Bardi, and Johanna Haapamäki. 2008. The interaction between values and organizational identification in predicting suggestion-making at work. Journal of Occupational and Organizational Psychology 81: 241-48. [CrossRef]

MacPherson, James S., and Steve W. Kelly. 2011. Creativity and positive schizotypy influence the conflict between science and religion. Personality and Individual Differences 50: 446-50. [CrossRef]

Maio, Gregory. R. 2016. The Psychology of Human Values. London: Psychology Press.

Maltby, John, and Liza Day. 2002. Religious experience, religious orientation and schizotypy. Mental Health, Religion \& Culture 5: 163-74.

Maltby, John, Iain Garner, Christopher Alan Lewis, and Liza Day. 2000. Religious orientation and schizotypal traits. Personality and Individual Differences 28: 143-51. [CrossRef]

Mason, Oliver, Yvonne Linney, and Gordon Claridge. 2005. Short scales for measuring schizotypy. Schizophrenia Research 78: 293-96. [CrossRef] [PubMed]

McCreery, Charles, and Gordon Claridge. 1995. Out-of-the-body experiences and personality. Journal of the Society for Psychical Research 60: 129-48.

Mohr, Sylvia, and Philippe Huguelet. 2004. The relationship between schizophrenia and religion and its implications for care. Swiss Medical Weekly 134: 369-76. [PubMed]

Musch, Jochen, Robbi Brockhaus, and Arndt Bröder. 2002. Ein Inventar zur Erfassung von zwei Faktoren sozialer Erwünschtheit [A scale to measure two factors of social desirability]. Diagnostica 48: 121-29. [CrossRef]

$\mathrm{Ng}$, Felicity. 2007. The interface between religion and psychosis. Australasian Psychiatry 15: 62-66. [CrossRef] [PubMed]

Olsen, K. A., and Bent Rosenbaum. 2006. Prospective investigations of the prodromal state of schizophrenia: Assessment instruments. Acta Psychiatrica Scandinavica 113: 273-82. [CrossRef]

Oman, Doug. 2013. Defining religion and spirituality. In Handbook of the Psychology of Religion and Spirituality, 2nd ed. Edited by R. F. Paloutzian and C. L. Park. New York: Guilford Press, pp. 23-47.

Paulhus, Delroy. L. 1984. Two-component models of socially desirable responding. Journal of Personality and Social Psychology 46: 598-609. [CrossRef]

Peters, Emanuelle. 2001. Are delusions on a continuum? The case of religious and delusional beliefs. In Psychosis and Spirituality. Exploring the New Frontier. Edited by I. Clarke. Philadelphia: Whurr, pp. 191-207.

Peters, Emmanuelle, Samantha Day, Jacqueline McKenna, and Gilli Orbach. 1999. Delusional ideation in religious and psychotic populations. British Journal of Clinical Psychology 38: 83-96. [CrossRef]

Piedmont, Ralph. L. 2009. Personality, spirituality, religiousness, and the personality disorders: Predictive relations and treatment implications. In Religion and Spirituality in Psychiatry. Edited by P. Huguelet and H. G. Koenig. Cambridge: University Press, pp. 173-89.

Reed, Phil, and Natasha Clarke. 2014. Effect of religious context on the content of visual hallucinations in individuals high in religiosity. Psychiatry Research 215: 594-8. [CrossRef]

Saha, Rahul, Shubh Mohan Singh, and Anil Nischal. 2015. Infanticide by a mother with untreated schizophrenia. Shanghai Archives of Psychiatry 27: 311-14. [CrossRef]

Saroglou, Vassilis, Vanessa Delpierre, and Rebecca Dernelle. 2004. Values and religiosity: A meta-analysis of studies using Schwartz's model. Personality and Individual Differences 37: 721-34. [CrossRef]

Schwartz, Shalom H. 1992. Universals in the content and structure of values: Theoretical advances and empirical tests in 20 countries. Advances in Experimental Social Psychology 25: 1-65.

Schwartz, Shalom. H., and Sipke Huismans. 1995. Value priorities and religiosity in four Western religions. Social Psychology Quarterly 58: 88-107. [CrossRef]

Schwartz, Shalom H., Gila Melech, Arielle Lehmann, Steven Burgess, Mari Harris, and Vicki Owens. 2001. Extending the cross-cultural validity of the theory of basic human values with a different method of measurement. Journal of Cross-Cultural Psychology 32: 519-42. [CrossRef] 
Simon, Bennett. 1978. Mind and Madness in Ancient Greece: The Classical Roots of Modern Psychiatry. Ithaca: Cornell University Press.

Smith, D. Brent, and Jill E. Ellingson. 2002. Substance versus style: A new look at social desirability in motivating contexts. Journal of Applied Psychology 87: 211-19. [CrossRef]

Smith, L., S. Riley, and Emmanuelle Peters. 2009. Schizotypy, delusional ideation and well-being in an American new religious movement population. Clinical Psychology \& Psychotherapy 16: 479-84. [CrossRef]

Stark, Rodney, and Charles Y. Glock. 1968. American Piety: The Nature of Religious Commitment. Berkeley: University of California Press.

Stein, Margit. 2016. Zusammenhänge zwischen Religionszugehörigkeit, Religiosität und Wertorientierungen: Eine internationale und nationale repräsentative Analyse auf Basis des Religionsmonitors [Associations between religious denominations, religiosity, and value orientation-An international and national representative analysis based on the monitor of religions]. Zeitschrift für Religionspädagogik 15: 173-204.

Thalbourne, Michael A. 1994. Belief in the paranormal and its relationship to schizophrenia-relevant measures: A confirmatory study. British Journal of Clinical Psychology 33: 78-80. [CrossRef] [PubMed]

Thalbourne, Michael A., and Peter S. Delin. 1993. A new instrument for measuring the sheep-goat variable: Its psychometric properties and factor structure. Journal of the Society for Psychical Research 59: 172-86.

Thalbourne, Michael A., and Christopher C. French. 1995. Paranormal belief, manic-depressiveness, and magical ideation: A replication. Personality and Individual Differences 18: 291-92. [CrossRef]

Tiliopoulos, Niko, and Annemieke Bikker. 2013. A thematic comparison of religiosity profiles between Christians with low and high schizotypy. Mental Health, Religion E Culture 16: 173-78. [CrossRef]

Unterrainer, Human F., Helmuth Paul Huber, I. M. Sorgo, Joanna Collicutt, and Andreas Fink. 2011. Dimensions of religious/spiritual well-being and schizotypal personality. Personality and Individual Differences 51: 360-64. [CrossRef]

White, Josephine, Stephen Joseph, and Alastair Neil. 1995. Religiosity, psychoticism, and schizotypal traits. Personality and Individual Differences 19: 847-51. [CrossRef]

Willard, Aiyana K., and Ara Norenzayan. 2017. "Spiritual but not religious": Cognition, schizotypy, and conversion in alternative beliefs. Cognition 165: 137-46. [CrossRef]

Wolfradt, Uwe, Viktor Oubaid, Eckart R. Straube, Natascha Bischoff, and Johannes Mischo. 1999. Thinking styles, schizotypal traits and anomalous experiences. Personality and Individual Differences 27: 821-30. [CrossRef]

Wulff, David M. 1997. Psychology of Religion: Classic and Contemporary Views. London: Wiley \& Sons. 